\title{
Strategic Thinking on the Teaching Reform of Environmental Design From the Future to the Present
}

\author{
Pei wen ying ${ }^{1, \mathrm{a}}$
}

Shanghai Institute of visual arts Shanghai China

\begin{abstract}
With the popularization and further evolution of artificial intelligence and computing technology, a large number of unemployed people and the demand for talents in new industries appear at the same time and change rapidly, so the reform of higher education is imminent. At present, the teaching of environmental art design is far from being able to cope with the social challenges of big data, and its own teaching system is fuzzier and uncertain due to the changes of industry needs and design ethics. Therefore, from the perspective of future changes and needs, this paper adopts the backward method and takes the strategic teaching reform in the direction of environmental design as a reference to provide future tendentious guidance for the reform of teaching in Colleges and universities.
\end{abstract}

Keywords: big data technology, environmental art design, teaching reform, social possibility, consciousness upgrading

\section{由未來向現在的環境設計教學改革策略性思辨}

\author{
裴纹英 ${ }^{1,2}$
}

上海视觉艺术学院 上海 中国

425855126.com

摘要:

随着人工智能和计算技术的推广应用和进一步进化，大量的失业人口和新行业人才需求同时出现并快 速更迭，高校教育改革已经迫在眉睫。而当下环境艺术设计专业 的教学在面临大数据的社会挑战上还 远远不具备应变能力, 自身的教学体系又因为行业需求和设计伦理的变化而显得更加模糊和不确定。 因此, 本文从未来的变化和需求出发, 采用倒推法, 以环境设计专业方向的策略性教学改革思辨作为 参照，给高校教学的改革提供未来倾向性指导。

关键词: 大数据技术、环境艺术设计、教学改革、社会可能、意识升级

\section{1. 大数据技术的达摩克利斯之剑已朝高校教 育挥来}

在托夫勒《第三次浪潮》、奈斯比特《大趋势》和
丹尼尔的《后工业社会的来临》并称“未来学三大经典” 出现的时候, 我们开始弹冠相庆, 因为我们迎来了历史 上最美好的时代, 这里有先进的技术, 个性化的社会服 务, 和便捷的网络物联系统 [1]。后来, 凯文. 凯利出来 了《失控》和《必然》, 我们开始知道大数据时代也不 是那么美, 在运算技术和生物计算的背景下, 人类生活 
将面临着大量的失业, 时间、环境与生存形态的压力令 人无法安生 $[2]$ 。到了尤瓦尔. 赫拉利的《未来简史》和 《今日简史》, $80 \%$ 的无用阶层, 和数据霸权下的信息 钳制, 使我们突然发现自己即将变成无用人群, 甚至我 们将会丧失真正意义上生存权利, 因此我们变得更加的 急迫、茫然和焦虑 [3]。如果说这些可能都还很远，那 么翻看一下 IBM 公司、Google 公司等技术力量近年来 在社会应用领域上的人工智能 [4] [5],我们就很清楚大 数据时代的达摩克利斯之剑已经向我们挥出, 就看我们 以什么样的方式来面对挑战了。

杜威曾经说知识教育是“转变旧的含义和新的形式 从而达成两者的融合”。在环境设计专业的技术含义中, 大数据技术早已对我们的生活环境造成非常大的影响, 小到个体的居住体验, 如智能化居住设备的定制, 由智 能材料提供的设计语言, 大到区域生活环境的改变, 如 无人驾驶技术的应用、共享汽车的普及，由交通方式变 革所带来的都市、城际公共空间的重新定义 [6]。更勿 论就已经大量投入使用与设计的手段 (各种渲染软件、 测绘软件等）、表现方式（如 3D 打印和 VR、AR 的叙事 介绍技术）、施工管理（BIM 标准化管理、物联网络、 一体化工程前置系统等)、行业测评(建筑云数据测评) 等等最实际迫切的变化。这些技术变革对环境设计行业 的最大冲击体现在未来的 5-8 年内, 将会有大批的中低 端的通用设计由计算技术直接完成, 而不需要日益增长 经济成本的设计师完成。

而从社会服务的角度分析，当技术经济领域“传播 到全社会, 并面临工具理性的要求时”, 将引发政治体 系和社会文化的变革 [1]。政治体系对社会的控制是首 要的, 是技术与经济产业前进的最后一道阀门, 也指导 着高校教育的定位与方向。因此在 “互联网 + ” 的教育 改革探索中,我们需要在行政公共关系的治理范畴中分 析环境设计专业面临的挑战和机遇。虽然高等教育中社 会文化的专业传播职能一直没有发生变化,但为社会服 务的内容、框架和组织形式却因为社会治理模式的不断 改革而发生的变化。基于科技治国的基本范畴，目前的 行政管理体系已经向新公共行政治理体系转化,并有着 一定的市场化管理痕迹 $[7]$, 其数字化的绩效考评还是 作为行政管理的基本依据。但由新公共关系所形成的社 会结构过于讲求协作、妥善而显得庞大, 再对具体事务 的执行推动中就显得低效和混乱 [8]。因此, 在以社区 管理和服务平台搭建为重要职责的地方部门眼里, 大学 院校的设计服务和学校专业所提的设计服务是两个不 同层级的概念。他们对环境艺术设计的社会服务不再是 单纯的设计类要求, 也不是配合行业或项目展开的设计 服务。而是希望我们能够扮演系统资源的整合、梳理、 策略咨询、项目执行及辅助转化的样板型工作, 或者提 供项目协作运营模式的指导与构建服务。所有的社会服 务已经进化为新公共治理体系旁的新公众参与共建型
的社会帮助转化。

从行业变化的需要出发, 近年来国内的传统制造业 在资源控制下或者通过创新科技与计算网络进行产业 升级和转化, 或者由整体的产业结构调整和红线限制逐 步被淘汰。在这样的经济形态上, 计算技术的相关行业 会被大力推动, 而更多地人口将转向服务行业, 社会消 费已呈现紧缩状态。而我们环境艺术设计专业对建筑设 计行业在 2014 年遭遇的断崖式下跌后, 并没有就社会 成因进行系统的分析, 以至于现在整体的环境艺术设计 教育还陷在一种 “迷之自信” 中, 且自娱自乐着。前几 年, 通过政府与产业革命导向的文化创意路径改革似乎 是给所有的大学设计类专业提供的一种狂欢的可能, 但 经济发展的原动力来源于产品的内涵增长, 服务业的利 润必然大大低于制造业。根据熵增定律，在没有超凡的 能量进入这个社会行业系统, 它的消耗将成不可逆的趋 势慢慢枯竭僵死。因此, 将文化与智能技术、大数据技 术的融合创新将是这种超凡能量的唯一出口。

\section{2. 我们现在在做什么样的教改}

以 2017 年全国各高校开展的 “毕业设计・环境设 计” 主题研讨会为资料来源 [10], 我们从环境艺术设计 专业的教学定位、专业特色、教学框架、教学方式和教 学目标等方面进行分析, 评估。

\section{$>$ 广州美术学院建筑艺术设计学院：}

\begin{tabular}{|l|l|}
\hline 教学定位 & “艺筑集成, 思行并重” \\
\hline 专业特色 & $\begin{array}{l}\text { 回归室内。注重室内空间的 } \\
\text { 边界和小尺度空间的推敲。 } \\
\text { 采用紧缩性社会指导设计的 } \\
\text { 理念 }\end{array}$ \\
\hline 教学框架 & $\begin{array}{l}\text { 教学框架专业包含建筑设 } \\
\text { 计、环境艺术设计和景观设 } \\
\text { 计三个专业方向, 提供的专 } \\
\\
\text { 业融合包含: 建筑、室内、 } \\
\text { 圆领、装饰艺术、工艺美 } \\
\text { 术、陶瓷艺术等。 } \\
\text { 采用 “ } 1+2+1 \text { ”的专业教学模 } \\
\text { 式, } 1 \text { 年基础课程, + } 2 \text { 年室 } \\
\text { 内设计为主的专业教学, 最 } \\
\text { 后 } 1 \text { 年跨专业主题性工作室 } \\
\text { 教学。毕设采取工作室制, 每 }\end{array}$ \\
\hline
\end{tabular}




\begin{tabular}{|c|c|}
\hline & $\begin{array}{l}\text { 个工作室由导师带领 4-6 名 } \\
\text { 学生完成主题设计, 包含城 } \\
\text { 市建筑、媒体空间、技术与 } \\
\text { 创意、艺术造境、室内设计 } \\
\text { 五个方向。 }\end{array}$ \\
\hline 教学方式 & $\begin{array}{l}\text { 探索性教学, 关注设计的方 } \\
\text { 法和观念, 不屈从于社会短 } \\
\text { 视的功利需求 }\end{array}$ \\
\hline 教学目标 & $\begin{array}{l}\text { 立足于广州地区的实证教育 } \\
\text { 基础, 带动区域市场与消费 } \\
\text { 的前沿, 解决社会问题, 在 } \\
\text { 空间上思辨未来可能。 }\end{array}$ \\
\hline
\end{tabular}

$>$ 四川美术学院设计学院环境设计系:

\begin{tabular}{|c|c|}
\hline 教学定位 & $\begin{array}{l}\text { “乡土再造、智慧创新、社会 } \\
\text { 服务” }\end{array}$ \\
\hline 专业特色 & $\begin{array}{l}\text { 一是厚基础、大背景。二是立足 } \\
\text { 土进行创新实践 }\end{array}$ \\
\hline 教学框架 & $\begin{array}{l}\text { 采用 “ } 1+1+X \text { 工作室制教学模 } \\
\text { 式。 } 1 \text { 年的基础教学, }+1.5 \text { 年专 } \\
\text { 业通识教育 (景观、室内两个方 } \\
\text { 向), }+X \text {, 是主题性 (非跨专 } \\
\text { 业) 的工作室课程 (包含主题设 } \\
\text { 计和毕业设计)。 } \\
\text { 目前四个工作室中, 两个景观 } \\
\text { (城乡环境景观设计, 地域文化 } \\
\text { 景观设计)、两个室内 (系统化 } \\
\text { 室内设计, 室内空间技术与环境 } \\
\text { 设计)。 }\end{array}$ \\
\hline 教学方式 & $\begin{array}{l}\text { 项目制实践教学, 材料、工艺的 } \\
\text { 技术导入, 国际工作坊课程 }\end{array}$ \\
\hline 教学目标 & $\begin{array}{l}\text { 强调未来学生的整合能力、灵活 } \\
\text { 应变的能力。同时注重区域教学 } \\
\text { 的特色, 如四川的山地地形的特 } \\
\text { 色设计。 }\end{array}$ \\
\hline
\end{tabular}

\begin{tabular}{|l|l|}
\hline 教学定位 & $\begin{array}{l}\text { 抓住时代特征, 直面社会问题, 解 } \\
\text { 决问题 }\end{array}$ \\
\hline 教学框架 & \begin{tabular}{l} 
包含建筑、城市、环艺、景观四 \\
个专业, 两个五年制（建筑与城 \\
市）、两个四年制 (环艺和景 \\
观)。采用 “ $1+2 / 3+1$ ” 的专业教 \\
学模式, 1 年基础课程, $+2 / 3$ 年 \\
的专业课程学习, 最后 +1 年跨专 \\
业主题性毕业设计。毕设采取实 \\
践课题, 导师带领完成主题探索性 \\
设计。 \\
\hline 教学方式 \\
希望通过实践课程完成设计服务 \\
与设计转化; 针对现有的社会变 \\
化, 培育学生的系统建构和开放 \\
能力。 \\
\hline 教学目标 \\
为人的更好生活而设计
\end{tabular} \\
\hline
\end{tabular}

$>$ 同济大学设计创意学院:

\begin{tabular}{|l|l|}
\hline 教学定位 & $\begin{array}{l}\text { 追求可持续的 “生活-空间生态系 } \\
\text { 统”。由生活内容出发的环境设 } \\
\text { 计, 重点关注信息数据交互系统的 } \\
\text { 空间设计。 }\end{array}$ \\
\hline 专业特色 & $\begin{array}{l}\text { 设计的变革。其中包含三个方面: } \\
\text { 可持续创新、学科交叉 (设计生态 } \\
\text { 系统)、以人为中心。 }\end{array}$ \\
\hline 教学框架 & $\begin{array}{l}\text { 采用 “ } 1+0.5+2+0.5 \text { ”专业教学模 } \\
\text { 式。 } 1 \text { 年的基础教学, }+0.5 \text { 年专业 } \\
\text { 基础课程 (传达设计) },+2 \text { 专业环 }\end{array}$ \\
\hline
\end{tabular}




\begin{tabular}{|c|c|}
\hline & $\begin{array}{l}\text { 境设计课程（交互空间为侧重 } \\
\text { 点）, +0.5 的毕业设计。 }\end{array}$ \\
\hline 教学方式 & $\begin{array}{l}\text { 侧重在环境设计思维方式和环境设 } \\
\text { 计的方法论构建。以空间和关系为 } \\
\text { 教学基础。 }\end{array}$ \\
\hline 教学目标 & 可持续的变革 \\
\hline
\end{tabular}

\section{$>$ 清华大学美术学院环境艺术设计系:}

\begin{tabular}{|c|c|}
\hline 教学定位 & 研究型高端环境艺术设计 \\
\hline 专业特色 & $\begin{array}{l}\text { 以人居环境为主要的设计对象, 强 } \\
\text { 调培养行业的适应性、高素质、复 } \\
\text { 合型人才 }\end{array}$ \\
\hline 教学框架 & $\begin{array}{l}\text { 采用 “ } 1+2.5+0.5 \text { ” 专业教学模 } \\
\text { 式。 } 1 \text { 年的基础教学, }+2.5 \text { 年专业 } \\
\text { 设计课程, }+0.5 \text { 的毕业设计, 同时 } \\
\text { 通过第三学期完成实践。 } \\
\text { 其中 } 2.5 \text { 年的专业基础课程包含核 } \\
\text { 心课程和选修课程, 核心课程是以 } \\
\text { 主题项目制的形式, 以点带面的完 } \\
\text { 成设计门类教学, 并以进阶式课程 } \\
\text { 群的方式完成。 }\end{array}$ \\
\hline 教学方式 & $\begin{array}{l}\text { 立足自身艺术特色, 在课程内完成 } \\
\text { 对社会变化所产生设计改变。 }\end{array}$ \\
\hline
\end{tabular}

以上五所大学环艺专业的教学模式呈现虽然不全 面, 从单一资料中获取的信息也会存在一定的误读, 但 基于所选资料的杂志的权威性,和这几所学校毕业设计 的作品呈现, 以上信息还是能相对代表目前国内环境艺 术设计的基本面貌。

因此,我们不难从这些信息中感受到各自面临变革 的迫切性和教学改革的思考。其中固然有一些教育层面 是稳定不变的, 如: 1) 、摆脱形式训练的窠臼, 回应 社会现实问题。2）、设计教学永远都处于趋向 “理想 的学科状态” , 但永远达不到。3）、设计教育的门类
本质核心没有变化, 变化的是设计门类的称呼和形式。 但也有一些教学改革的思考：1）、相对于建筑专业科 学传统的桎梏, 使得向国家城市建设提供人才的宽度较 小, 因此变革的机遇需要凸显在相对灵活的设计学科上。 2）、应对日益增长的社会信息和资源，应该用批判性 的创新思维来构建设计教学。3) 、教学组织模式中, 师生双方关系也将重新调整, 老师将扮演更多的咨询角 色。4）、对于空间思维方式和空间知觉还是需要依赖 制图来完成。

可从本文的角度来分析, 各大院校的问题并不仅限 于此。首先, 作为教学目标 “为社会服务” 这一点上。 面对社会问题, 基本所有的高校还是固守在设计服务的 层次, 对上下级机构的衔接与转化是被动的, 信息、技 术和转化资源的不了解就会造成设计院校的不落地, 对 行业和社会问题背后逻辑伦理关系的不完整解读也会 造成教学理解和定位的偏差。其次, 不论从项目制教学 到具体的平台式设计服务的教学方法的改革探索; 还是 从通用性设计到沉浸式设计的教学内容改革探索; 还是 从跨专业联合的主题研究型毕业设计到主题性的校际 联合国际工作坊的组织形式的改革探索, 都还是在一个 教学平台上, 学术专业上的封闭会造成技术类和社会科 学类学科、社会技术团队的难于介入, 也会使自身的可 持续性变得更脆弱。然后, 关于教学定位和专业特色, 目前国内高校的办学策略还是依据现有老师团队和资 源特长来定义自身的办学特色。它造成的结果一方面就 体现在大学教师考核体系和学科建设的相互捆绑中, 高 等教育的学术版块壁垒越加深厚, 另一方面人才与教学 内容选拔标准的单一也限制和消耗了大量教师的创造 性可能。这两个都是将大学的社会职能剥离与教学系统。 因此面对真实的社会问题, 目前大学专业的适应力、创 造力和社会指导的能力就已经很薄弱了。最后, 教学的 师生关系在现有的设计院校内, 相对于别的学科貌似要 灵活亲切很多, 但如果把它放在创造性团队内, 其组织 方式和授课的空间营造上还是固化死板得多。很多高校 将实践课程、田野调查和工作坊的形式作为课程的补充 是很好的选择, 但由于项目课题定案的随机性, 这种变 化的课程形式普遍和学科可持续发展的衔接并不紧密, 效能就低很多。

整体来说, 目前高校的环境艺术设计在教学的出口 端, 是处于被社会需要和经济行业选择的境地。当然高 等教育貌似近几十年都不会被淘汰, 但数据技术引发的 变革并不表现为 “在推倒你的废墟上坚立新的旗帜” , 而是在它的系统里形成适应它的设计服务系统而已, 如 同信息时代替代了机械时代, 线上销售替代了实体店销 售一样。 


\section{3. 现有的技术将产生什么需要, 提供什么可 能}

在上世纪 60-70 年代, 丹尼尔. 贝尔在对 “后工业 时代” 的描述中, 我们将有 $45 \%$ 的人将面临失业的危机 [1]，在 2016 年吴军的 “智能时代” 的描述中，只有 $2 \%$ 的受益者 [4]，而在同期尤瓦尔. 赫拉利的《未来简史》 中则清晰的预言在 2030 年左右在建筑业将会有 $88 \%$ 建 筑工人, $72 \%$ 的木工会失业。目前, 集成式装配结合智 能化设施已经被运用在成品居住空间内, 它对家具与环 境产品设计师的容量已经大大缩减。在不久的将来, 人 居环境的中低端普遍性设计需求必然也会缩减。在常规 的思维模式中: 随着旧职业被淘汰, 会有新职业出现, 人类总有些事情做得比机器更好。那么, 新的职业到底 将是在什么样的社会环境中存在?

在未来我们生存的环境将会是 “人机共生” 状态, 这是大家的共识, 但关键的问题是共生的情境是怎么样 的？对我们设计教育的改革有什么启示？一方面人工 智能的自我学习能力会促使知识的更新频率大过人类 认知学习的频率, 另一方面, 政治系统和社会文化部门 会在和科学机构结合利用共享的数据和信息抢占有效 资源的同时，也会对技术的野蛮发展进行消化和控制。 因此, 从资源传承和转移的趋势上判断, 大学教育改革 的本质是争取机会的优先权, 而不是结果的表述权。我 们需要思考的要素无非是三个层级: 社会公共性和创造 性的结合; 人机交互学的重新建构; 设计意识 (人机共 生下的智能与社会第二序思维意识的抢夺）的再定义。 因此, 对不同学校的环艺专业来说, 这是一个很美好的 时代, 因为存在着弯道超车的机会, 也是一个很糟糕的 时代, 因为存在着过多的不确定性, 即使改变也可能被 淘汰。但如果你不改变, 或者认知不够清晰, 那么你会 无知无觉的死亡!

\section{4. 路在脚下，快走上來}

依据教学建设的特点, 和高校资源等级分配的规则, 在由清晰的未来导向的倒推中, 我们可以从教学体系、 教学团队、教学内容三个方面论述环艺教学改革的框架。

在未来的教学体系中, 环艺设计将会有两个方向。 一个方向是能够运用新社会心理和社会现象学下的设 计师。将技术交给计算工程师和生物工程师来解决, 将 设计伦理和设计概念交给自己,依据计算提供的系统相 关关系以及彼此的绩效结构比例, 用自身的艺术创造特 长在社会行业中占一席之地。另一个方向是为机器和智 能服务, 成为行业制造环节的设计翻译, 或程序流程的 设计, 以及帮助完成界面交互的设计师。这是现在的设 计工程师的社会型艺术升级版。
四川美院曾经提出: 学科定位并不需要急切的确定 我们 “为谁而服务” 。《今日简史》和 《后工业社会的 到来》中都有很多的论述 [9], 大学院校的教育目标和 对象定位都不需要清晰的确认,一方面因为技术发展的 速度变化太快, 社会的不确定性太强, 另一方面是由于 信息的庞大和交叉会导致设计学科的相关专业也很庞 大,而学生接受信息的速度和来源要比学校和老师来的 快而多, 因此, 专业知识与技能的灌输必然会被退化, 取而代之的是思辨性的思维和建构认知的方法论会更 被需要。专业的定位会弱化，学科融合会被强调。

相应的,时间的因素也应该反映在我们的教学体系 中。大量的基础性和技术性课程可以通过网络和计算技 术在短时间内由学生们自我导入和完成, 而设计理念的 培育, 和与其他学科的融合协作, 则需要花一定的时间 来进行磨合。因此, 基础通识教育的构成会需要重新调 整, 电脑技术和学科协作的学时投入和教学比重会增大。 同时, 教学的时间周期也应该更开放更自由, 表现为在 校教育、网络互动式教学、和继续学习的相互开放融合 上，其实这也会节约教育成本的有效途径。

教学团队的改革是基于办学理念的改革而成的。我 们现在已经面临着学生了解知识的路径和新兴创新案 列比我们快和多的情况。老师们需要在不断学习中前置 完成教学内容的构建, 同时需要调整自身在教学组织中 的定位, 而这一切并不能仅仅靠教师自身就能够完成, 除了学校本身的考核机制和教学结构需要发生变化, 教 师团队的成长和学校教学方式的开放度, 以及学校在地 方社会服务平台中的定位也密切相关。

教学内容的设置上, 应该关注哲学、心理学研究、 社会现象学对设计思维的影响和交叉, 同时在基础通识 课程和主题设计中增添计算工程、生物工程的技术与思 维对设计重构。

在特色课程建设中, 地方传统文化的传承与保护课 题由于其技术介入的成本过高而与低收效不匹配等原 因, 在近几十年内将仍由设计师和文化工作者把握 [3], 因此从人类历史学和文化创新产业的角度, 衍生的系统 性设计与社会服务的转化将仍然会是我们课题建设的 重地之一。其次在 “人机共生” 的社会生态中，“人文 关怀” 语境出发, 注重人性体验的叙事设计也还会是设 计专业的主题风向。因为在共生环境下，对于环境社会 的认知所引发的 “共情” 是最具备人文价值的, 它能通 过心理和故事的叙述有效帮助人们明晰自身在社会变 化中的位置和彼此间的联系 [13], 同时它具备着信息学 的基本语言功能, 也是最容易衔接机器语言和逻辑的方 式 [14], 因此, 作为人性体验和计算思维融洽结合的设 计方法论更新模式, 具备了良好的教学模本。同时 “为 人机共生而设计” 自然也会是不变的研究课题, 如何运 用创意设计的手段，更人性、更便捷、更趣味的对人机 
交互、计算 . 设计翻译等课题进行设计, 并兼顾通用、 易读和容错等方向的具体研究, 都将会是不错的选择。

总之, 就如同济大学设计创意学院娄永琪提出的论 点: 设计的最终的产出不再是一个结果, 而是过程, 甚至 是一个开放的过程。包含了物质设计和非物质设计之间 综合作用的一种平衡, 以及这种平衡因时因势而变的可 能性。在变化的过程和在过程中的变化系统内, 由创想 构成的设计教学思考才是符合大数据时代的教育的基 本特征。

\section{5. 是意识反攻, 还是思维反哺}

在未来教育面貌描述的反推中, 我们清晰的知道环 艺设计教育的培养目标是要教导学生能够有创造力的 思考。除了设计思维的启发, 更重要的是要培养学生敢 创想、敢构建 “什么样的社会” ，以及这个社会背后的 逻辑关系。法国艺术评论家尼可拉. 布西欧说 “艺术是 最能够创造新的社会关系”，我们的学生只有具备对未 来社会做出各种不确定的, 异想天开式的设计构想和想 象的能力, 才能够在理性的技术环境中开始有资格去增 加我们生活的话语权,才能够增加对自身生活的自由选 择的可能, 也才能够增加社会特征的多样性。因此, 我 们的环境艺术设计教育应该是在设计的第二序哲学、心 理学等范畴内展开的形而上研究, 或形而下的服务。

所以, 我们必须从这个角度来预先设立教学改革思 维, 才能够应对不久就会到来的这一场由计算技术和人 工智能引发社会变革。因此, 这是艺术意识的反攻, 也 是对未来设计的思维反哺。

\section{References}

[1] Daniel Bell, the coming of post industrial society, Jiangxi people's publishing house, 2018.

[2] Kevin Kelly, out of control, New Star Press, 2010.

[3] Yuval herali, a brief history of the future, CITIC press, 2017.

[4] $\mathrm{Wu}$ Jun, intelligent age: big data and intelligent revolution redefine the future, CITIC press, 2016

[5] Jerry Kaplan, the age of artificial intelligence, Zhejiang People's publishing house, 2016

[6] Robin Li, intellectual revolution, CITIC press, 2017.

[7] Habermas, structural transformation of the public sphere, Xuelin press, 1999.

[8] Janet v. Denhardt, new public service, Renmin
University of China Press, 2004

[9] Yuval herali, a brief history of today, CITIC press, 2018.

[10] 2017 "graduation design environmental design" theme seminar, "decoration", July 2017.

[11] Qian Danian, Zhang Zhexi, "the dilemma and Countermeasures for the cultivation of innovative and entrepreneurial talents in Colleges and universities in the era of education 4.0", education and teaching forum, October 2016, issue 43

[12] Chen Tan, Liu Cheng, "education reform towards the era of industry 4.0", Nanjing Social Sciences, 2016, Issue 9

[13] D.P. McAdams, The Stories We Live By, Morrow, New York, 1993.

[14] T.R. Sarbin, Narrative Psychology: The Storied Nature of Human Conduct, New York, 1986.

[15] Roman Jakobsons, Language in Literature, Belknap Press, 1988.

[16] Anthony Dunne, Fiona Raby, 《 Speculative Everything》, MIT press, 2014.

[17] What is entropy? How to explain it to others in a simple and understandable way? 》, https://www.zhihu.com/question/19753084?sort=created

[18] What's the difference and connection between information entropy and entropy in thermodynamics and statistical physics? https://www.zhihu.com/question/20992022

[19] Reading notes of education revolution in the age of artificial https://book.double.com/subject/27040869/

[20] Relationship Aesthetics: https://www.state.org.uk/art 